\title{
Efficiency of Moroccan Seaports: Application of DEA Using Window Analysis
}

\author{
Mahdi Birafane', Moad El Abdi² \\ ${ }^{1}$ College of Transport and Communications, Shanghai Maritime University, Shanghai, China \\ ${ }^{2}$ Department of Physics Engineering and Science, Shanghai, China \\ Email:mahdi.birafane@hotmail.com,moad.elabdi@gmail.com
}

How to cite this paper: Birafane, M. and El Abdi, M. (2019) Efficiency of Moroccan Seaports: Application of DEA Using Window Analysis. Engineering, 11, 107-118. https://doi.org/10.4236/eng.2019.112009

Received: January 24, 2019

Accepted: February 25, 2019

Published: February 28, 2019

Copyright (c) 2019 by author(s) and Scientific Research Publishing Inc. This work is licensed under the Creative Commons Attribution International License (CC BY 4.0).

http://creativecommons.org/licenses/by/4.0/

\begin{abstract}
The efficiency of 8 seaports in the Kingdom of Morocco region was evaluated. Two associated studies were conducted based on data collected for 4 years (2014-2017), Standard Data Envelopment Analysis (DEA) method was used in the first analysis through CCR and BCC models, and thus a scale of efficiency analysis was used in a second analysis. By using both methods, enhanced insight into the efficiency situation is collected, proving subsequently that a majority of the container ports and terminals in the Kingdom of Morocco are found to be technically inefficient. The research concludes through returns to scale method how port resources should be utilized in the aim to impulse inefficient ports perform better.
\end{abstract}

\section{Keywords}

Moroccan Seaports, Data Envelopment Analysis, Seaports Efficiency, BCC Model, CCR Model, Returns to Scale Method

\section{Introduction}

The maritime transport of goods plays a vital role in the foreign trade of Morocco; it ensures good competitiveness in terms of logistics cost and the processing time of cargoes. Recently, the maritime connectivity of this country has been improved significantly placing the country in the 16th position worldwide. Apart from the different type of exchanges, which is carried out mainly by direct sea freight or by combined transport Ro-Ro, another type was added during the last decade, that is to say the activity of containers transshipment. This activity is concentrated at the Port of Tangier Med which was connected to 163 world ports in 2014. This means assessing capabilities and measuring efficiencies of major ports of the Kingdom of Morocco is a necessary approach in order to 
drive inefficient ports perform well. To increase the efficiency and cargo volume traded, the hub-strategy should be implemented by each port i.e. one place can handle all types of container traffic; this will develop the trade capacity of the port [1]. However, production capabilities and the efficiency measurement of seaports have always been a main concern in seaport organization. To overcome this issue, a Data Envelopment Analysis (DEA) was always implemented by seaport researchers in the aim to measure performance of their ports.

Previously, many studies using DEA method were pursued by several researchers to assess the efficiency of their seaports; however, most of these studies evaluated the efficiency of seaports located in the European countries [2] [3] [4] [5], but the number of researchers was declining significantly regarding the African countries. Nevertheless, none of the studies conducted so far have focused on seaports in the Kingdom of Morocco. This paper focuses on this strategic region which is seen by foreigner liners as a gate to the world.

The present research study analyses effective efficiency of selected major ports in the Kingdom of Morocco during 2014-2017 through a Data Envelopment Analysis, in the aim to determine inefficient ports and provide clarification thereof. It also tries to investigate whether length berth is inducing the operational efficiency. The study used input variables based on platform size and berth Length and Equipment, whereas output variables were represented by container traffic and total cargo traffic of the selected major ports. The following section will mainly introduce the port characteristics of assessed ports, and then a literature review on port efficiency will be highlighted. In the third section a research methodology will be explained by exploring the Data Envelopment Analysis (DEA) framework. The empirical results and the analysis will be presented and discussed in the fourth section. The final section summarizes the finding and provides accordingly some recommendations.

\section{Port Characteristics}

Over the past decades, seaport industry in the Kingdom of Morocco has witnessed remarkable changes in several perplex forms; that is to say in one hand the increasing demand of containerization, RO-RO, liquid and solid bulk, respectively for inward and outward flows; entailing some seaports terminal to expand their platform, as the capacity was reached respectively for Casablanca and Tangier Port.

In the other hand the Samir refinery, which makes Mohammedia region the center of the Moroccan petroleum industry, had a considerable impact on the activity of its seaport, thus the performance level cannot be measured efficiently, in doing so the Port of Mohammedia is not included in the present analysis.

The selected seaports for our study are considered to be the major ports in Morocco, they have provided facilities for the regional coasters and as time went by, they have developed to be among the maritime transshipments ports for the African maritime routing. For instance the geographic strategic location of Tan- 
gier MED seaport, which is considered as a gate to Europe have encouraged pioneering liners (e.g. Maersk Group and CMA-CGM) to invest in this strategic hub to make calls for their vessels. These major seaports of Morocco and their characteristics are displayed in Table 1.

The characteristics of major seaports in Morocco in 2017 presented in Table 1 show that Tangier Med is ranked first in terms of total processing tonnage which is explained obviously by its major activity of transshipment platform hub, then it is followed by Casablanca Port which is considered as the center of the commercial activity of the country, other ports like Jorf Lasfar, Safi, Agadir, Laayoune and Dakhla are listed respectively in the decreasing order.

Figure 1 shows the traffic by conditioning mode excluding free trade zone of Tangier MED 1 seaport, as it is indicated the major national seaport traffic consist of solid bulk, followed respectively by liquid bulk, containers and cargo.

Table 1. Characteristics of major seaports in the Kingdom of Morocco in 2017.

\begin{tabular}{ccccccc}
\hline No. & Port & $\begin{array}{c}\text { Berth } \\
\text { Length }\end{array}$ & Equipment & $\begin{array}{c}\text { Area } \\
\text { M sq }\end{array}$ & $\begin{array}{c}\text { Container } \\
\text { Throughput } \\
\text { “TEU” }\end{array}$ & $\begin{array}{c}\text { Total } \\
\text { Throughput } \\
\text { "Tons" }\end{array}$ \\
\hline 1 & Nador & 1780 & 13 & $1,430,000$ & 33 & $2,686,745$ \\
2 & Tanger Med & 2200 & 89 & $1,400,000$ & $3,312,409$ & $51,328,150$ \\
3 & Casablanca & 8000 & 74 & $2,560,000$ & 986,926 & $31,002,476$ \\
4 & Jorf Lasfar & 2439 & 21 & $1,100,000$ & 0 & $29,598,292$ \\
5 & Safi & 2348 & 15 & 530,000 & 0 & $6,152,651$ \\
6 & Agadir & 1344 & 9 & 680,000 & 202,654 & $4,971,334$ \\
7 & Laayoune & 1391 & 5 & 166,000 & 0 & $2,661,138$ \\
8 & Dakhla & 300 & 3 & 20,000 & 396 & 650,257 \\
\hline
\end{tabular}

Source: The Moroccan national port agency "ANP", Marsa Maroc, and Tanger Med Special Agency "TMSA" 2018.

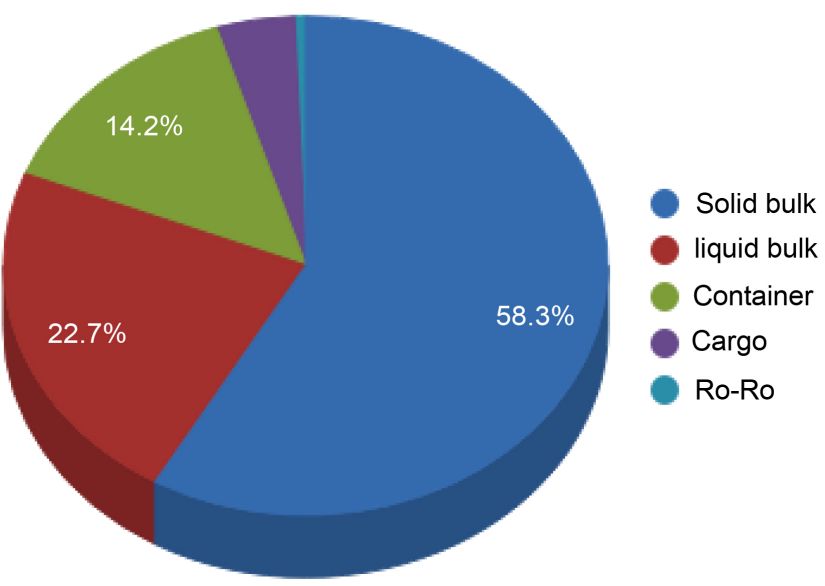

Figure 1. Traffic breakdown by conditioning mode in 2017. Source: https://www.anp.org.ma/En/Agency/Pages/ANPfigures.aspx. 


\section{Literature Review}

Efficiency is the (often quantifiable) capability to circumvent wasting materials, energy, efforts, money, and time in doing something or in producing a desired result. In a more general sense, it is the ability to do things well, successfully, and without waste.

DEA is one the bold approaches which empirically measure productive efficiency of decision making units (or DMUs), it has been used for both cost data and production. Using the designated variables, such as unit cost and output, DEA software looks for the points with the bottom unit cost for any specified output, linking those points to form the efficiency frontier. Any firm not on the frontier is viewed inefficient.

Recently many studies have been conducted to evaluate performance as well as efficiency of seaport in different region. On one hand, Rajasekar et al. [1] examine the operational efficiency of major ports in India over the period of time 1993 to 2011 through Data Envelopment Analysis (DEA) and they concluded that size does not determine port efficiency. On the other hand, Al-Eraqi et al. [6] study the efficiency of 22 seaports in the Middle East and East African region, and concluded that small ports are efficient while big ports are inefficient. A drawback of this technique is that it was identified that very few studies have measured operational efficiency with the combination of input and output oriented DEA models [1]. Furthermore, Berg [7] points out that model specification of this technique and inclusion/exclusion of variables can affect the results.

Another perplex of this technique is that there's no unified selection of variables; every author has its own range of defined set, Coto-Millan et al. [8], Valentine and Gray [9], Al-Eraqi [6] and Liu [10] selected traffic tons as output variable. However, for the second output some of them use ship calls (e.g. Al-Eraqi, Mustaffa, Khade and Barros [6]), others use container throughputs as an output variable, because the most suitable indicator to evaluate the ports' production is the annual container throughput in TEUs, as the main purpose of any container terminal is to handle as many containers as possible [11]. Likewise, most authors defined Number of Equipment as an input variable [6] [10] [12] [13] [14]; conversely, Roll and Hayuth [15] and Rios and Maçada [12] selected Number of Employee as another input variables. Furthermore, two studies use non-conventional indicators as inputs or outputs. de Almeida Guimarãesa, Juniorb and de Almada Garcia [16] evaluate the environmental performances of fifteen Brazilian container terminals by using the consumption of non-renewable energy, total energy consumption, sewage emissions, office supply consumption, $\mathrm{CO}_{2}$ emissions, and water consumption as inputs and container throughput as an output. Kuang and Li [17] evaluate the efficiencies of 13 typical port-listed-companies in China by taking into consideration net permanent assets and total employees as input factor and the main business revenues as an output. 
Finally in the general perspective, no study have been reported using DEA analysis for the major ports of the Kingdom of Morocco, even though it's a primordial approach by which logistics decision makers should opt for it in order to evaluate in the efficient way the measurement of performance of the selected seaport. In this regard the present study will subsequently help the later port authorities to determine the weakness as well as the advantages in both input and output oriented data envelopment model.

\section{Data Envelopment Analysis}

Data Envelopment Analysis (DEA) is a "data oriented" method for assessing the performance of a set of peer units called Decision Making Units (DMUs) which convert several inputs into multiple outputs. The definition of a DMU is standard and flexible [18].

The modern years have witnessed a great variety of usage of DEA for application of evaluating the performances of many different types of entities involved in many various activities in many different contexts in many different countries. These DEA applications have used DMUs of several forms to evaluate the performance of units, such as universities, seaports, cities, utilities, business firms, and others, including the performance of countries, regions, etc. Because it requires very few assumptions, DEA has also opened up possibilities for use in cases which have been resistant to other approaches because of the complex (often unknown) nature of the relations between the multiple inputs and multiple outputs involved in DMUs [18].

There are two types of models in DEA: radial and non-radial. The non-radial models, e.g., the slacks-based measure of efficiency (SBM) model, handle input or output slacks directly, and do not assume proportional changes of inputs or outputs. The SBM model was introduced by Tone. It has three variations, i.e., input-, output-, and non-oriented. The non-oriented model indicates both input- and output-oriented, which can be measured as follow:

$$
\begin{aligned}
\min & \frac{1-(1 / m) \sum_{i=1}^{m}\left(s_{i k}^{-} / x_{i k}\right)}{1+(1 / s) \sum_{r=1}^{s}\left(s_{r k}^{+} / y_{r k}\right)} \\
\text { s.t. } & \sum_{j=1}^{n} \lambda_{j k} x_{i j}=x_{i k}-s_{i k}^{-}, \quad \forall i, \\
& \sum_{j=1}^{n} \lambda_{j k} y_{r j}=y_{r k}+s_{r k}^{+}, \quad \forall r, \\
& \lambda_{j k}, s_{i k}^{-}, s_{r k}^{+} \geq 0, \quad \forall j, i, r
\end{aligned}
$$

where $n$ is number of DMU $(k=1, \cdots, n), m$ and $s$ are respectively inputs and outputs of each DMU, $x_{i j}$ and $y_{r j}$ are respectively vectors of inputs and outputs for $D M U_{j}$, Thus $x_{i j}=\left(x_{1 j}, x_{2 j}, \cdots, x_{m j}\right)^{\mathrm{T}}$ and $y_{r j}=\left(x_{1 j}, x_{2 j}, \cdots, x_{s j}\right)^{\mathrm{T}}$, $\lambda_{i j}=\left(\lambda_{1 j}, \lambda_{2 j}, \cdots, \lambda_{n}\right)^{\mathrm{T}}$ is called the intensity vector.

However radial models are represented by the CCR (Charnes-Cooper-Rhodes) model. Basically, they deal with proportional changes of inputs or outputs, In this regard we propose in this paper the output-oriented DEA model to maximize the 
output whereas the given current inputs remain the same, the mathematical formulation of the DEA models will be simplified as follows:

1) CCR Model.

$$
\begin{aligned}
& \text { s.t. } \sum_{j=1}^{n} \lambda_{j} x_{i j} \geq x_{i k}, \forall i ; \\
& \quad \sum_{j=1}^{n} \lambda_{j} y_{r j} \leq \varnothing_{k} y_{r k}, \forall r
\end{aligned}
$$

And 2) BCC Model (Banker, Charnes and Cooper [19]) is defined by adding Equation (3) to expression (2) above.

$$
\sum_{j=1}^{n} \lambda_{j}=1
$$

where $\varnothing_{k}$ is the efficiency of $D M U_{k}$,

The above BCC model measures Technical Efficiency as the convexity constraint and ensures that the composite unit is of similar scale size as the unit being measured. The resulting efficiency is always at least equal to the one given by the CCR model, and those DMUs with the lowest input or highest output levels are rated efficient. Unlike the CCR model which is shown in Expression (2), the BCC model shown in Equation (3) allows for variable returns to scale, but both models are based on radial projections to the production frontier. However, many other approaches give freedom to the projection so that the final efficient targets do not conserve the mix of inputs and outputs [20].

In the circumstance of benchmarking, the efficient DMUs, as defined by DEA, may not necessarily form a "production frontier", but rather lead to a "bestpractice frontier" [21]. DEA is stated as "balanced benchmarking" by Sherman and Zhu [22]. Non-parametric approaches have the benefit of not assuming a specific functional form/shape for the frontier, but they do not supply a common relationship (equation) connecting output and input.

In the present study, MaxDEAPro 6.6 software developed by Cheng Gang and Qian Zhenhuato (2009-2015) was used to assess the selected port, since it has the most extensive range of the up-to-date DEA models. Both input and output oriented models were stimulated seeking to maximize the outputs, minimize the inputs and maximize the efficiency. In general, input oriented model closely focus on operational and managerial issues whereas output oriented model are more oriented towards planning and strategy [14].

\section{Results \& Discussion}

Table 2 shows the relative efficiency of seaports using DEA-CCR results and its ranking for selected major ports in Morocco. The obtained results are highlighted based on the efficiency score from 0.00 to 1.00 . It means units who obtain a score of precisely 1.00 will be considered as efficient and less than this score will be treated subsequently inefficient.

From Table 2, it is evident that the ports of Tangier Med I and Jorf Lasfar were proved to be efficient ports during the overall studied period 2014-2017, these ports have a stable and efficient performance. However, in a general 
Table 2. Standard DEA-CCR.

\begin{tabular}{cccccccc}
\hline No. & Seaports & 2014 & 2015 & 2016 & 2017 & Mean & Rank \\
\hline 1 & Nador & 0.226 & 0.210 & 0.215 & 0.147 & 0.199 & 8 \\
2 & Tanger Med & 1.000 & 1.000 & 1.000 & 1.000 & 1.000 & 1 \\
3 & Casablanca & 0.506 & 0.511 & 0.532 & 0.509 & 0.515 & 6 \\
4 & Jorf Lasfar & 1.000 & 1.000 & 1.000 & 1.000 & 1.000 & 1 \\
5 & Safi & 0.632 & 0.476 & 0.443 & 0.401 & 0.488 & 7 \\
6 & Agadir & 0.726 & 0.731 & 0.823 & 0.749 & 0.757 & 4 \\
7 & Laayoune & 0.853 & 0.622 & 0.660 & 0.547 & 0.670 & 5 \\
8 & Dakhla & 0.771 & 0.875 & 1.000 & 0.887 & 0.883 & 3 \\
\hline
\end{tabular}

Source: Author.

context Nador, Casablanca, Safi, Agadir and Laayoune Ports show inefficiency over the studied years, thus Nador, Safi and Nador Ports are performing critically since their score is very low varying from 0.632 to 0.147 .

The Port of Dakhla shows also inefficiency during 2014-2015 but with an increased performance until 2016 where the port becomes efficient, then it declined gradually reflecting inefficient score from 2016 to 2017.

Based on the average result of DEA-CCR analysis, Tangier Med and Jorf-Lasfar Ports jointly occupied the first position of the ranking list, followed by Dakhla, Agadir and Laayoune Port that are ranked respectively in third, fourth and fifth position. The lowest positions were obtained in a descending scale by Casablanca, Safi, and Nador Port.

Table 3 of relative efficiency of seaports using DEA-BBC indicates that another port joined the list of efficient ports compared to the previous result of Table 2 "DEA-CCR standard" the ports of Tangier Med, Jorf Lasfar and Dakhla Port this time were proved to be efficient ports during the overall studied period 2014-2017. However, other three ports Nador, Casablanca and Safi Port are still inefficient during the overall studied years putting into evidence their inefficient performance for both analyses.

The Port of Laayoune showed efficient performance in 2014, and then became inefficient port since 2015. Agadir Port is performing in a fluctuating manner by providing an efficient yield through the last years 2016-2017, but being inefficient during the first two years 2014-2015.

For the current parameter of analysis the top ports are Tangier Med, Jorf Lasfar and Dakhla Port sharing together the first position of the podium, subsequently followed by Agadir ranked forth, and Laayoune ranked fifth. In the lower positions Casablanca Port ranked sixth, Safi Port ranked seventh and finally Nador Port ranked last.

Relative efficiency analysis of selected major ports in Morocco during 2014-2017 was done and results are presented from Tables 4-7. The model finds out efficient as well as inefficient units and the reasons thereof. The value for scale efficiency is obtained by dividing the aggregate efficiency by the technical 
Table 3. Standard DEA-BCC.

\begin{tabular}{cccccccc}
\hline No. & Seaports & 2014 & 2015 & 2016 & 2017 & Mean & Rank \\
\hline 1 & Nador & 0.246 & 0.230 & 0.235 & 0.161 & 0.218 & 8 \\
2 & Tanger Med & 1.000 & 1.000 & 1.000 & 1.000 & 1.000 & 1 \\
3 & Casablanca & 0.674 & 0.670 & 0.684 & 0.666 & 0.673 & 6 \\
4 & Jorf Lasfar & 1.000 & 1.000 & 1.000 & 1.000 & 1.000 & 1 \\
5 & Safi & 0.655 & 0.485 & 0.449 & 0.408 & 0.499 & 7 \\
6 & Agadir & 0.939 & 0.972 & 1.000 & 1.000 & 0.978 & 4 \\
7 & Laayoune & 1.000 & 0.793 & 0.810 & 0.688 & 0.823 & 5 \\
8 & Dakhla & 1.000 & 1.000 & 1.000 & 1.000 & 1.000 & 1 \\
\hline
\end{tabular}

Source: Author.

Table 4. The relative efficiency of seaports using DEA-CCR and DEA-BCC models in 2014.

\begin{tabular}{cccccc}
\hline No. & DMU & DEA-CCR & DEA-BCC & Scale efficiency & Return to scale \\
\hline 1 & Nador & 0.226 & 0.246 & 0.920 & Increasing \\
2 & Tanger Med I & 1.000 & 1.000 & 1.000 & Constant \\
3 & Casablanca & 0.506 & 0.674 & 0.752 & Decreasing \\
4 & Jorf Lasfar & 1.000 & 1.000 & 1.000 & Constant \\
5 & Safi & 0.632 & 0.655 & 0.965 & Increasing \\
6 & Agadir & 0.726 & 0.939 & 0.773 & Increasing \\
7 & Laayoune & 0.853 & 1.000 & 0.853 & Increasing \\
8 & Dakhla & 0.771 & 1.000 & 0.771 & Increasing \\
\hline
\end{tabular}

Source: Author.

Table 5. The relative efficiency of seaports using DEA-CCR and DEA-BCC models in 2015.

\begin{tabular}{cccccc}
\hline No. & DMU & DEA-CCR & DEA-BCC & Scale efficiency & Return to scale \\
\hline 1 & Nador & 0.210 & 0.230 & 0.914 & Increasing \\
2 & Tanger Med I & 1.000 & 1.000 & 1.000 & Constant \\
3 & Casablanca & 0.511 & 0.670 & 0.763 & Decreasing \\
4 & Jorf Lasfar & 1.000 & 1.000 & 1.000 & Constant \\
5 & Safi & 0.476 & 0.485 & 0.980 & Increasing \\
6 & Agadir & 0.731 & 0.972 & 0.752 & Increasing \\
7 & Laayoune & 0.622 & 0.793 & 0.784 & Increasing \\
8 & Dakhla & 0.875 & 1.000 & 0.875 & Increasing \\
\hline
\end{tabular}

Source: Author.

efficiency. In this regard the score report indicates that only two seaports "Tangier Med and Jorf Lasfar" operated as efficient ports among selected major ports in Morocco. Whereas other ports like Nador, Casablanca, Safi, Laayoune and Dakhla showed inefficient in utilization of their inputs factors during the whole 
Table 6. The relative efficiency of seaports using DEA-CCR and DEA-BCC models in 2016.

\begin{tabular}{cccccc}
\hline No. & DMU & DEA-CCR & DEA-BCC & Scale efficiency & Return to scale \\
\hline 1 & Nador & 0.215 & 0.235 & 0.915 & Increasing \\
2 & Tanger Med I & 1.000 & 1.000 & 1.000 & Constant \\
3 & Casablanca & 0.532 & 0.684 & 0.777 & Decreasing \\
4 & Jorf Lasfar & 1.000 & 1.000 & 1.000 & Constant \\
5 & Safi & 0.443 & 0.449 & 0.988 & Increasing \\
6 & Agadir & 0.823 & 1.000 & 0.823 & Increasing \\
7 & Laayoune & 0.660 & 0.810 & 0.814 & Increasing \\
8 & Dakhla & 1.000 & 1.000 & 1.000 & Constant \\
\hline
\end{tabular}

Source: Author.

Table 7. The relative efficiency of seaports using DEA-CCR and DEA-BCC models in 2017.

\begin{tabular}{cccccc}
\hline No. & DMU & DEA-CCR & DEA-BCC & Scale efficiency & Return to scale \\
\hline 1 & Nador & 0.147 & 0.161 & 0.913 & Increasing \\
2 & Tanger Med & 1.000 & 1.000 & 1.000 & Constant \\
3 & Casablanca & 0.509 & 0.666 & 0.764 & Decreasing \\
4 & Jorf Lasfar & 1.000 & 1.000 & 1.000 & Constant \\
5 & Safi & 0.401 & 0.408 & 0.984 & Increasing \\
6 & Agadir & 0.749 & 1.000 & 0.749 & Increasing \\
7 & Laayoune & 0.547 & 0.688 & 0.794 & Increasing \\
8 & Dakhla & 0.887 & 1.000 & 0.887 & Increasing \\
\hline
\end{tabular}

Source: Author.

period, expect in 2016 where Dakhla Port showed efficient scale. As consequence several measures should be followed by port authorities of these ports in order to become efficient whether by affecting more resources to the business or by reducing it subsequently.

From Tables 4-7, it is seen that seaports like Nador, Safi, Agadir and Laayoune are in increasing returns to scale during the entire studied period from 2014 to 2017 that implies one percent increase inputs will certainly lead to an increase of output by more than one percent. Whereas Casablanca Port is in decreasing returns to scale so any increases in inputs (both equipment and area) would lead to an increase in output less than one percent. Dakhla Port also showed an increasing returns to scale during three years expect for the period of 2016 where it reflects a constant return to scale meaning that an increase of inputs by a specific amount will lead to an increase of output by the same amount.

In order to explore more deeply the DEA analysis, the below graph (Figure 2) indicates an example of some resources that need to be utilized efficiently, in other word we conducted an analysis of berth length and find out that Casablanca Port is above the VRS efficiency frontier, which means it is possible to 


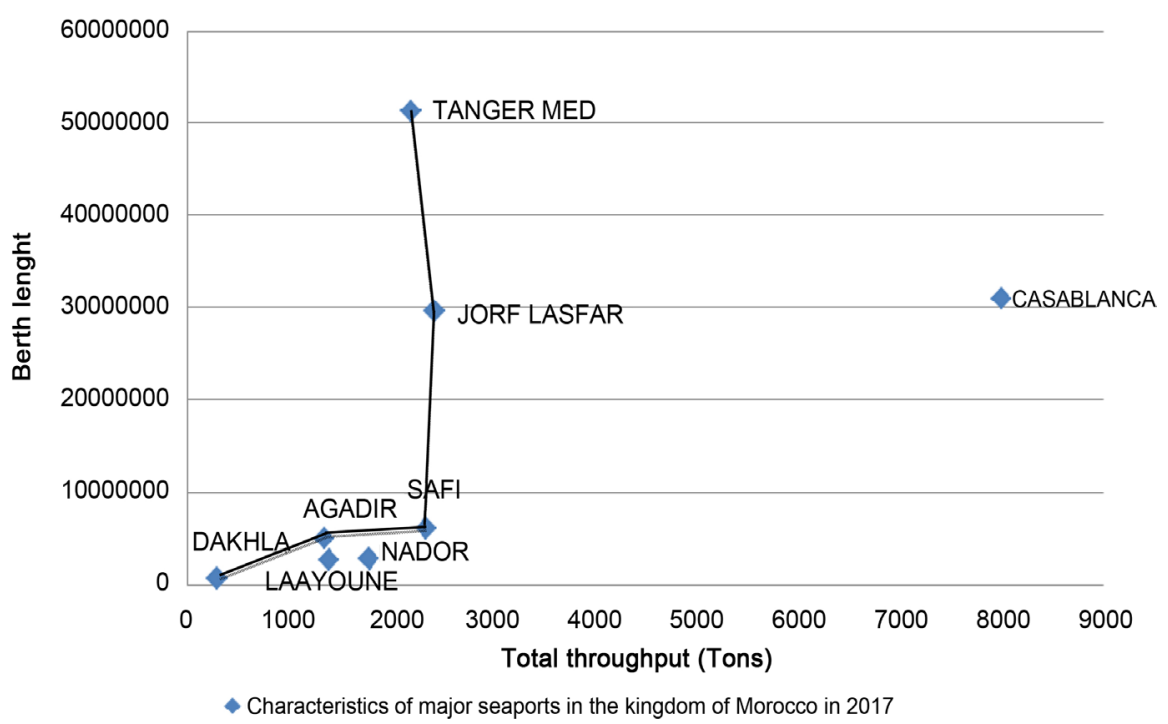

Figure 2. Efficiency frontier of Moroccan major ports in 2017. Source: Author.

reduce the berth length to between $2000 \mathrm{~m}$ and $2500 \mathrm{~m}$ and keeping the same output as Jorf Lasfar proven to be efficient with lower berth length. Other ports below the efficiency frontier such as Dakhla Port need to increase their berth length in the aim to maximize the output performance.

\section{Conclusions and Recommendations}

According to the present study, big ports are not necessarily most efficient ones, and size factor is not the only performance indicator. There are too many other factors that should be utilized efficiently in a combined and proper way for better outcomes. Port of Casablanca has one of the highest inputs in terms of berth length, area and equipment, but is the only port which is seen to have a decreased return to scale; therefore, Casablanca Port authorities should think to put in place some extension facilities operated by pioneering port management firms rather than investment in increasing their resources. In fact, the available resources are not utilized efficiently, since the VRS frontier result indicates that Casablanca Port authorities have the possibility to reduce their berth length to between $2000 \mathrm{~m}$ and $2500 \mathrm{~m}$. Furthermore, other key success factors should be utilized efficiently, such as handling equipment, workforce performance and import-export formalities processing time. This will allow port authorities to tackle the inefficiency problem from their origin.

Although Dakhla Port has the smallest resources in the Kingdom of Morocco, in 2016 it was among the efficient ports next to Tangier Med and Jorf Lasfar. Other ports like Nador, Safi, Agadir and Laayoune only need to increase their inputs in the aim to improve their outputs.

Finally, Tangier and Jorf Lasfar were the only two ports in Morocco reflecting efficient results during 2014-2017, which meant that the port management authorities should keep their bold performance and invest more in the development field. Thus, they could expect and face the future increasing demand. 


\section{Acknowledgements}

The authors are grateful to the ports authorities for providing data and information.

\section{Conflicts of Interest}

The authors declare no conflicts of interest regarding the publication of this paper.

\section{References}

[1] Rajasekar, T., Sania Ashraf, P. and Malabika Deo, P. (2014) Measurement of Efficiency of Major Ports in India, a Data Envelopment Analysis Approach. International Journal of Environmental Sciences, 4.

[2] Trujillo, L. and Tovar, B. (2007) The European Port Industry: An Analysis of Its Efficiency. Maritime Economics and Logistics, 9, 148-171.

https://doi.org/10.1057/palgrave.mel.9100177

[3] Barros, C.P. (2006) A Benchmark Analysis of Italian Seaports Using Data Envelopment Analysis. Maritime Economics \& Logistics, 8, 347-365. https://doi.org/10.1057/palgrave.mel.9100163

[4] Barros, C.P. and Manolis, A. (2004) Efficiency in European Seaports with DEA: Evidence from Greece and Portugal. Maritime Economics \& Logistics, 6, 122-140. https://doi.org/10.1057/palgrave.mel.9100099

[5] Cullinane, K., Ji, P. and Wang, T.F. (2006) The Efficiency of European Container.

[6] Al-Eraqi, A.S., Mustaffa, A., Khader, A.T. and Barros, C.P. (2008) Efficiency of Middle Eastern and East African Seaports: Application of DEA Using Window Analysis. European Journal of Scientific Research, 23, 597-612.

[7] Berg, S. (2010) Water Utility Benchmarking Measurement, Methodologies, and Performance Incentives. IWA Publishing, Vol. 9, 1-80.

[8] Coto-Millan, P., Banos-Pino, J. and Rodriguez-Alvarez, A. (2000) Economic Efficiency in Spanish Ports: Some Empirical Evidence. Maritime Policy Management, 27, 169-174. https://doi.org/10.1080/030888300286581

[9] Valentine, V.F. and Gray, R. (2001) The Measurement of Port Efficiency Using Data Envelopment Analysis. Proceedings of the 9 th World Conference on Transport Research, Seoul, 22-27 July 2001.

[10] Liu, C. (2008) Evaluating the Operational Efficiency of Major Ports in the Asia Pacific Region Using Data Envelopment Analysis. Applied Economics, 40, 1737-1743. https://doi.org/10.1080/00036840600905126

[11] Kutin, N., Nguyen, T.T. and Vallée, T. (2017) Relative Efficiencies of ASEAN Container Ports based on Data Envelopment Analysis. The Asian Journal of Shipping and Logistics, 33, 67-77.

[12] Rios, L.R. and Maçada, A.C.G. (2006) Analyzing the Relative Efficiency of Container Terminals of MERCOSUR Using DEA. Maritime Economics \& Logistics, 8, 331-346. https://doi.org/10.1057/palgrave.mel.9100168

[13] Wu, J. and Lin, C. (2008) National Port Competitiveness: Implications for India. Management Decisions, 46, 1482-1507. https://doi.org/10.1108/00251740810920001

[14] Cullinane, K., Wang, T.F. and Ji, P. (2005) The Relationship between Privatization and DEA Estimates of Efficiency in the Container Port Industry. Journal of Eco- 
nomics and Business, 57, 433-462. https://doi.org/10.1016/j.jeconbus.2005.02.007

[15] Roll, Y. and Hayuth, Y. (1993) Port Performance Comparison Applying Data Envelopment Analysis. Maritime Policy and Management, 20, 1-12. https://doi.org/10.1080/03088839300000025

[16] Guimarãesa, V.A., Juniorb, I.C.L. and Garcia, P.A.A. (2014) Environmental Performance of Brazilian Container Terminals: A Data Envelopment Analysis Approach. Procedia-Social and Behavioral Sciences, 160, 178-187. https://doi.org/10.1016/j.sbspro.2014.12.129

[17] Kuang, H. and Li, H. (2009) Research on X-Efficiency Measure of Chinese Ports, Systems Engineering. Theory \& Practice, 29, 1-9.

[18] Cooper, W.W., Seiford, L.M. and Zhu, J. (2011) Handbook on Data Envelopment Analysis. International Series in Operations Research \& Management Science Book Series, ISOR, Volume 164, 1-39.

[19] Banker, R.D., Charnes, A. and Cooper, W.W. (1984) Model for Estimating Technical and Scale Efficiencies in Data Envelopment Analysis. Management Science, 30, 1078-1092. https://doi.org/10.1287/mnsc.30.9.1078

[20] Aparicio, J., Lopez-Espin, J.J., Martinez-Moreno, R. and Pastor, J.T. (2014) Benchmarking in Data Envelopment Analysis: An Approach Based on Genetic Algorithms and Parallel Programming. Advances in Operations Research, 2014, 1-9.

[21] Cook, W.D., Tone, K. and Zhu, J. (2014) Data Envelopment Analysis: Prior to Choosing a Model, Omega. The International Journal of Management Science, 44, 1-4.

[22] Sherman, H.D. and Zhu, J. (2013) Analyzing Performance in Service Organizations. Sloan Management Review, 54, 37-42. 